К. В. Базіло, к.т.н., дочент

Черкаський державний технологічний університет вул. Шевченка, 460, Черкаси, 18006, Україна

\title{
ДОСЛІДЖЕННЯ ЕЛЕКТРИЧНОГО ІМПЕДАНСУ П'ЄЗОЕЛЕКТРИЧНОГО ДИСКУ В ОБЛАСТІ СЕРЕДНІХ ЧАСТОТ
}

Дискові п'єзоелектричні пристрої широко застосовуються в елементах інформаційних систем. Множинність і різноманіття практичного застосування дисків із секторним електродуванням природним чином стимулює теоретичні дослідження, метою яких є прогнозування характеристик і технічних параметрів пристроїв n'єзоелектроніки, які створюються на їх основі. Прогноз здійснюється на основі математичної моделі, яка є основним результатом теоретичного опису реального пристрою.

Ключові слова: n'єзоелектричний дисковий елемент, фізичні процеси, електричний імпеданс.

\section{Вступ}

П'єзоелектричні диски з частковим електродуванням однієї або двох поверхонь досить часто використовуються для створення різних функціональних пристроїв п'єзоелектроніки [1]. Дискові п'єзоелектричні пристрої широко застосовуються в елементах інформаційних систем [2-6]. Диски 3 секторним електродуванням поверхні $є$ практично основним елементом багатьох мікроелектромеханічних структур [7]. Множинність і різноманіття практичного застосування дисків 3 секторним електродуванням природним чином стимулює теоретичні дослідження, метою яких є прогнозування характеристик і технічних параметрів пристроїв п'єзоелектроніки, які створюються на їх основі. Прогноз здійснюється на основі математичної моделі, яка $\epsilon$ основним результатом теоретичного опису реального пристрою. Практична значимість адекватної реальному об'єкту математичної моделі очевидна. В результаті дослідження математичної моделі реального пристрою можна визначити той набір геометричних, фізико-механічних та електричних параметрів реального об'єкта, який забезпечує реалізацію технічних показників функціонального елементу п'єзоелектроніки, обумовлених в технічному завданні. Це істотно скорочує час i вартість розробки нових функціональних елементів п'єзоелектроніки. Вартість зекономлених ресурсів становить комерційну ціну математичної моделі.

Основною метюю даної статті $є$ дослідження електричного імпедансу дискових п'єзокерамічних елементів в області середніх частот.
1. Дослідження п'сзоелектричного диску в області середніх частот

Розглянемо (рис. 1) диск, товщина якого $\alpha$ в багато разів менше радіуса $R$. Поверхні диску $z=0$ i $z=\alpha$ ( $z$ - координатна вісь циліндричної системи координат $\rho, \varphi, z$, початок якої суміщено 3 центром нижньої поверхні диску) електродовані - покриті тонким (не більше 10 мкм) шаром срібла. На верхню поверхню $Z=\alpha$ подається електричний потенціал $U_{0} e^{i \omega t}\left(U_{0}-\right.$ амплітудне значення електричного потенціалу, величина якого вибирається 3 умови $U_{0} / \alpha<<0,1 E_{0}$, де $E_{0} \cong 2 \mathrm{MB} / \mathrm{M}$ - напруженість електричного поля, яке поляризує матеріал диску, що гарантує відсутність нелінійних ефектів; $i=\sqrt{-1}-$ уявна одиниця; $\omega$ - кругова частота зміни знаку потенціалу; $t$ - час). Нижня електродована поверхня $z=0$ заземлена, тобто має нульовий потенціал.

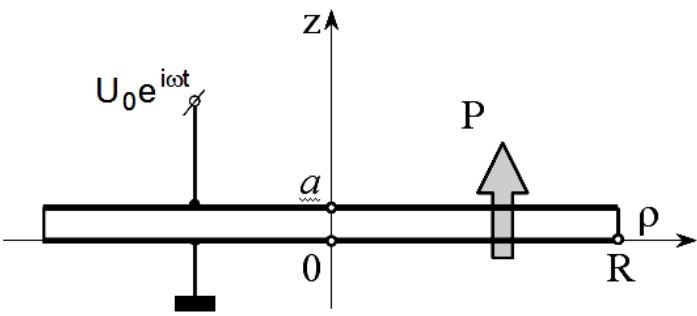

Рис. 1. Розрахункова схема коливального п’єзокерамічного диску

Прикладена до диска різниця електричних потенціалів створює в його об'ємі електричне поле, яке зміщує іони цирконію, тита- 
ну, свинцю і кисню 3 положення рівноваги. В результаті гармонійно змінного в часі деформування диску в ньому виникають поляризаційні заряди, які взаємодіють на електродованих поверхнях з електричними зарядами, які доставляються на ці поверхні генератором різниці електричних потенціалів. Результуючий електричний заряд $Q e^{i \omega t}$ на поверхні $z=\alpha$ своїм електричним полем формує електричний струм $I e^{i \omega t}$ у провіднику, який з'єднує поверхню $z=\alpha$ з виходом електричного генератора. У будь-який момент часу $I e^{i \omega t}=-\partial Q / \partial t=-i \omega Q e^{i \omega t}$, тобто амплітуди струму i електричного заряду на поверхні $z=\alpha \quad$ зв'язані $\quad$ лінійною залежністю $I=-i \omega Q$.

Очевидно, що електричний імпеданс $Z_{e l}(\omega)$ коливального диску повинен підкорятися закону Ома для ділянки кола, з чого випливає, що

$$
Z_{e l}(\omega)=\frac{U_{0}}{I}=-\frac{U_{0}}{i \omega Q} .
$$

Середніми частотами будемо називати частотний діапазон, в якому масштабна одиниця просторової неоднорідності напруженодеформованого стану (довжина пружної хвилі) стає співмірною 3 радіусом п'єзокерамічного диска.

В роботі [8] наведено розрахунок електричного імпедансу коливального диску, який можна записати в наступному вигляді:

$$
Z_{e l}(\omega)=\frac{1}{i \omega C_{\partial}^{*}} F^{(*)}(\omega),
$$

де

$$
F^{(*)}(\omega)=\frac{\lambda R J_{0}(\lambda R)-(1-k) J_{1}(\lambda R)}{\lambda R J_{0}(\lambda R)-\left(1-k-2 K_{31}^{2}\right) J_{1}(\lambda R)} ;(3)
$$

$K_{31}^{2}=\left(e_{31}^{*}\right)^{2} /\left(c_{11} \chi_{33}^{*}\right)$ - квадрат коефіцієнта електромеханічного зв'язку п'єзокераміки в режимі радіальних коливань диска, поляризованого по товщині; $C_{\partial}^{*}=\pi R^{2} \chi_{33}^{*} / \alpha$ - динамічна електрична ємність п'єзокерамічного диску для режиму планарних коливань, тобто електрична ємність в області середніх частот; $\chi_{33}^{*}=\chi_{33}^{\varepsilon}\left(1+\Delta \chi_{33}^{*}\right)$ - діелектрична проникність для режиму планарних коливань; добавка $\Delta \chi_{33}^{*}=e_{33}^{2} /\left(\chi_{33}^{\varepsilon} c_{33}^{E}\right)[8]$.
Функція $F^{(*)}(\omega)$, що задана виразом (3), має ряд характерних точок на вісі частот $\omega$. На частоті $\omega_{r m}$, котра відповідає $m$-му за номером кореню рівняння

$$
x J_{0}(x)-(1-k) J_{1}(x)=0,
$$

функція $F^{(*)}\left(\omega_{r m}\right)=0$. Слідом за частотами $\omega_{r m}$ радіальних резонансів слідують частоти, на яких обертається в нуль знаменник виразу (3). На цих частотах функція $F^{(*)}(\omega)$ необмежено зростає. Відповідно до цього необмежено зростає електричний імпеданс $Z_{e l}(\omega)$ п'єзокерамічного диску. Щоб підкреслити специфіку і відмінність цього стану від стану на частотах електромеханічного резонансу, частоту $\omega_{a m}$, на котрих $Z_{e l}\left(\omega_{a m}\right) \rightarrow \infty$, називають частотами електромеханічного антирезонансу.

У реальному експерименті нулі і нескінченності відсутні, оскільки в реальних пружних матеріалах завжди існують втрати на в'язке тертя. Ці втрати можна врахувати за допомогою параметру $Q_{\mu}$, який має сенс механічної добротності матеріалу. Як відомо, добротністю називається безрозмірне число, величина якого обернено пропорційна втратам енергії в коливальній системі за період. В ідеальних пружних тілах, де втрати енергії на в'язке тертя відсутні, $Q_{m} \rightarrow \infty$. У реальних об'єктах добротність $Q_{м}$ має кінцеве значення.

На рис. 2 показана зміна модуля електричного імпедансу п'єзокерамічного диску в діапазоні середніх частот (рис. 2,a). На вставці в поле рис. 2, а показана зміна значень модуля $Z_{e l}(\omega)$ в найближчій околиці частоти $\omega_{r 1}$ першого електромеханічного резонансу. На рис. 2,б показано зміна модуля електричного імпедансу в околиці частоти $\omega_{a 1}$ першого електромеханічного антирезонансу. Геометричні і фізико-механічні параметри диска, які використовувалися при обчисленнях за формулою (2) були прийняті наступними: радіус п'єзокерамічного диску $R=33 \cdot 10^{-3} \mathrm{M}$; товщина $\alpha=3 \cdot 10^{-3}$ м; параметри матеріалу диска (п'єзокераміки): $c_{11}^{E}=110$ ГПа; $c_{12}^{E}=60$ ГПа; $c_{33}^{E}=100$ ГПа; $e_{33}=18$ Кл $/ \mathrm{m}^{2} ; e_{31}=-8$ Кл $/ \mathrm{m}^{2}$ и 
$\chi_{33}^{\varepsilon}=1400 \chi_{0} ; Q_{M}=100 ; k=c_{12} / c_{11}=0,324$.

По осі ординат відкладені значення модуля електричного імпедансу в кілоомах, по осі абсцис відраховується безрозмірна частота $\Omega=\lambda R=\omega \tau_{0}$, де $\tau_{0}=R / v$ - часовий масштаб; $v=\sqrt{c_{11} / \rho_{0}}-$ швидкість поширення пружних

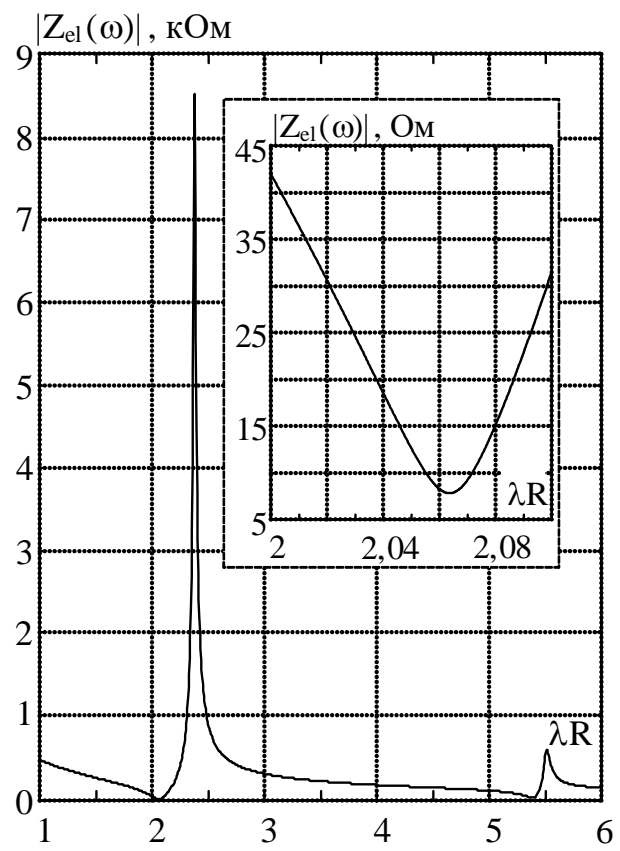

коливань у тонкому диску. Для наведених вище значень параметрів $v=3162 \mathrm{~m} / \mathrm{c}$ i $\tau_{0}=10,44 \cdot 10^{-6}$ с. Значенню $\Omega=\lambda R=1$ від-

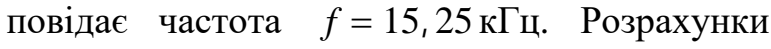
були виконані на частотах перших двох електромеханічних резонансів.

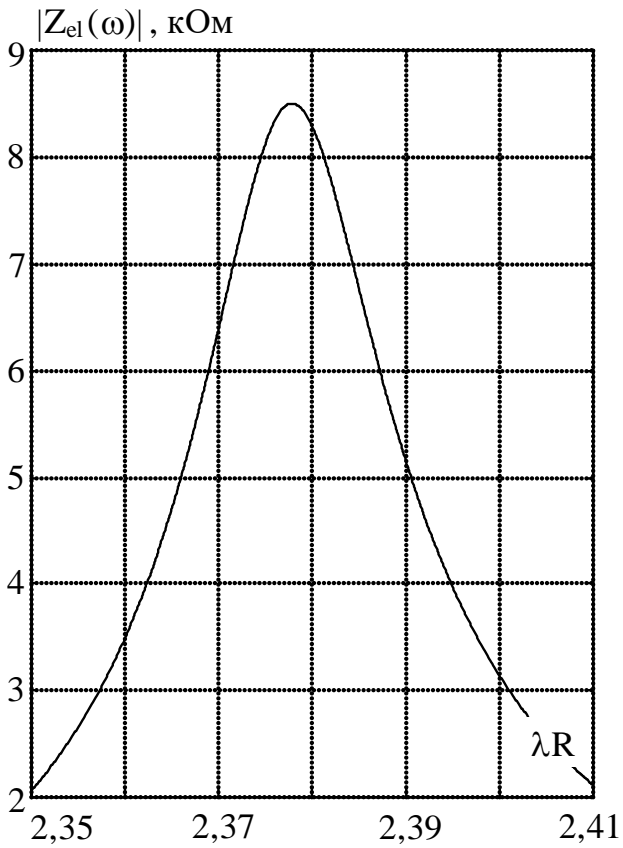

Рис. 2. Модуль електричного імпедансу диска в області середніх частот

В роботі [9] розглянуто методику експериментального визначення електричного імпедансу п'єзокерамічного диску. Схема для проведення експериментальних досліджень наведена на рис. 3.

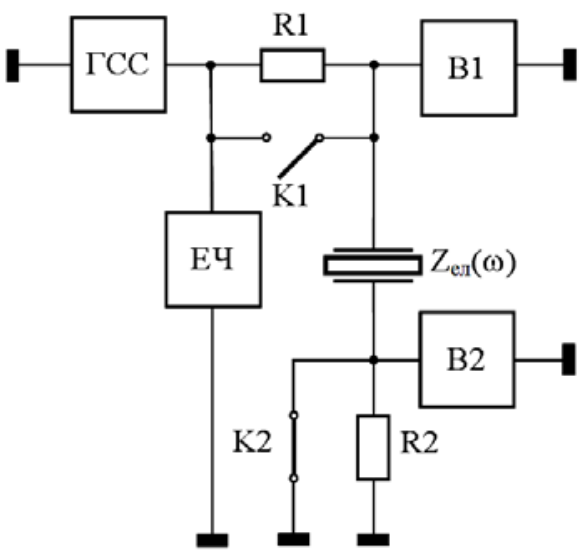

Рис. 3. Електрична схема для вимірювання електричного імпедансу п'сзокерамічного диску
Для виконання експериментальних досліджень використовувалися масивні диски. При цьому мінімізуються ефекти, пов'язані 3 приєднаною масою, яка виникає в процесі пайки провідників до електродованих поверхонь диску.

При вимірюванні електричного імпедансу $Z_{e l}(\omega)$ диск підвішувався в повітрі на тонких нитках для того, щоб уникнути механічного контакту з іншими об'єктами.

На схемі (рис. 3) абревіатурою ГСС позначений генератор синусоїдальних сигналів, ЕЧ - електронний частотомір, В1 і В2 - електронні вольтметри, К1 і К2 - ключі, що механічно замикаються й розмикаються, R1 i R2 навантажувальні резистори. Символом $Z_{e l}(\omega)$ на рис. 3 позначений досліджуваний зразок. Показане на схемі положення ключів К1 і К2 відповідає режиму вимірювання електричного імпедансу в околиці частоти електромеханічного резонансу. Навантажувальні резистори R1 i R2 підбираються таким чином, 
щоб вольтметри В1 і В2 працювали в діапазоні своєї максимальної чутливості, тобто на шкалах $(1 \div 10)$ м $B$. Величини резисторів R1 i R2 повинні бути визначені 3 точністю до одного Ома.

Для експериментальних досліджень був використаний дисковий п'єзоелектричний елемент Ø66×3 мм з матеріалу типу ЦТС.

Результати вимірювання електричного імпедансу п'єзоелектричного диску в області середніх частот представлені на рис. 4.

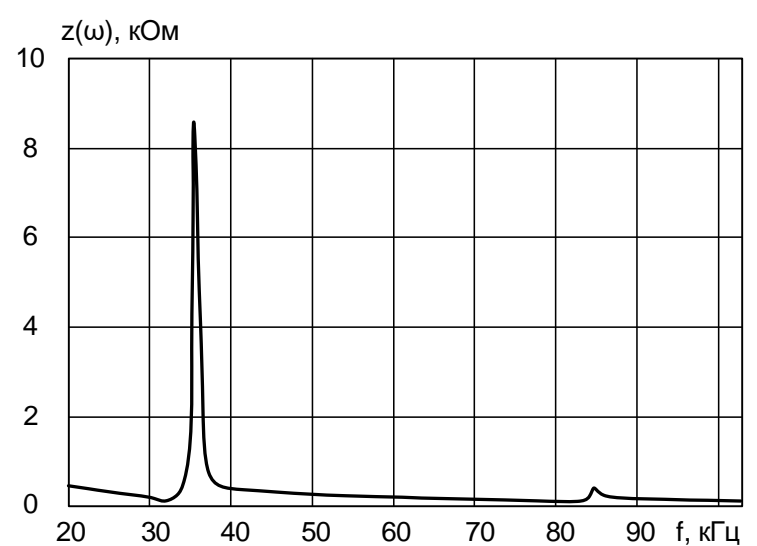

Рис. 4. Електричний імпеданс п'єзоелектричного диску в області середніх частот

При порівнянні результатів математичного моделювання електричного імпедансу п'єзоелектричного диску в області середніх частот (рис. 2), виконаних згідно $з$ виразом (2), та результатів експериментального вимірювання, наведених на рис. 4, видно, що отримана оцінка добре узгоджується 3 істинним значенням електричного імпедансу. При цьому значенню $\Omega=\lambda R=1$ відповідає частота $f=15,25$ кГц.

\section{Висновки}

Основний результат цієї статті можна зафіксувати наступним чином: отримана оцінка електричного імпедансу п'єзоелектричного диску в області середніх частот добре узгоджується з істинним його значенням.

\section{Список літератури}

1. Джагупов Р. Г., Ерофеев А. А. Пьезоэлектронные устройства вычислительной техники, систем контроля и управления. СПб.: Политехника, 1994. 608 с.

2. Piazza G., Stephanou P. J., Pisano A.P. A1N Contour-Mode Vibrating RF MEMS for Next generation Wireless Communications , MEMS 2006, pp. 906-909, 2006.

3. Li S. S., Lin Y. W., Xie Y., Nguyen C. C. $1.51 \mathrm{GHz}$ polydiamond micromechanical disk resonator with impedance-mismatched isolating support. Proceedings 17th Int. IEEE MEMS Conf., Maastricht, The Netherland, Jan. 25-29, 2004, pp. 821-824.

4. Y. W. Lin, S. S. Li， Z. Ren, C. C. Nguyen Third-Order Intermodulation Distortion in Capacitevely-Driven michromechanical resonators. IEEE Int. Ultrasonic Symposium, Sept. 18-21, 2005, pp.1592-1595.

5. Ruby R. "Micromachined cellular filters, Microwave Symposium Digest", IEEE MTT-S International, pp. 370-377, 1996.

6. Lakin M. K., Kline G. R., McCarron K. T. Thin Film Bulk Acoustic Wave Filters for GPS, Ultrasonics Symposium, 1992. Proceedings, IEEE 1992.

7. Варадан В., Виной К., Джозе К. ВЧ МЭМС и их применение. М.: Техносфеpa, 2004. $528 \mathrm{c}$.

8. Петрищев О. Н., Базило К. В. Определение электрического импеданса пьезокерамического диска и его расчет в области средних и высоких частот. Вісник Черкаського державного технологічного університету. Серія: Технічні науки. 2016. № 3. С. 36-49.

9. Петрищев О. Н., Базило К. В. Методика определения физико-механических параметров пьезоэлектрической керамики. Журнал нано- та електронної фізики. Суми. 2017. Т. 9, № 3, 03022(6cc).

\section{References}

1. Dzhagupov, R. G. and Erofeev, A. A. (1994) Piezoelectronic device of computing, control and monitoring systems. St. Petersburg: Politehnika, 608 p. [in Russian]

2. G. Piazza, P. J. Stephanou, A. P. Pisano, (2006) A1N Contour-Mode Vibrating RF MEMS for Next generation Wireless Communications , MEMS 2006, pp. 906-909.

3. S. S. Li, Y. W. Lin, Y. Xie, C. C. Nguyen, 1.51 (2004) GHz polydiamond micromechanical disk resonator with impedancemismatched isolating support. Proceedings, 17th Int. IEEE MEMS Conf., Maastricht, The Netherland, Jan. 25-29, pp. 821-824.

4. Y. W. Lin, S. S. Li， Z. Ren, C. C. Nguyen (2005) Third-Order Intermodulation Distor- 
tion in Capacitevely-Driven michromechanical resonators. IEEE Int. Ultrasonic Symposium, Sept. 18-21, pp.1592-1595.

5. R. Ruby (1996) "Micromachined cellular filters, Microwave Symposium Digest", IEEE MTT-S International, pp. 370-377.

6. M. K. Lakin, G. R. Kline, K. T. McCarron. (1992) Thin Film Bulk Acoustic Wave Filters for GPS, Ultrasonics Symposium, 1992. Proceedings, IEEE.

7. Varadan V., Vinoy K., Jose K. (2004) RF MEMS and their applications. Moscow: Texnosfera, 528 p. [in Russian]
8. Petrishchev O. N., Bazilo C. V. (2016) Determination of electrical impedance of piezoceramic disk and its calculation in medium and high frequency region. Visnyk of Cherkasy State Technological University, No. 3, pp. 36-49. [in Russian]

9. Petrishchev O. N., Bazilo C. V. (2017) Methodology of Determination of Physical and Mechanical Parameters of Piezoelectric Ceramics. Journal of Nano- and Electronic Physics, Vol. 9 No. 3, 03022(6pp). [in Russian]

C. V. Bazilo, Ph. D. (Eng.), Assoc. Prof.

Cherkasy State Technological University

Shevchenko blvd, 460, Cherkasy, 18006, Ukraine

\section{RESEARCH OF ELECTRICAL IMPEDANCE OF PIEZOELECTRIC DISK IN MIDDLE FREQUENCIES AREA}

Disk piezoelectric devices are widely used in the elements of information systems. The multiplicity and variety of the practical application of disks with sector electrodes naturally stimulates theoretical studies, the purpose of which is to predict the characteristics and technical parameters of piezoelectronic devices that are created on their basis. Prediction is based on a mathematical model, which is the main result of a theoretical description of a real device.

Keywords: piezoelectric disk element, physical processes, electrical impedance.

Стаття надійшла 04.06.2018.

Рецензенти: В. В. Палагін, д.т.н., професор,

В. С. Антонюк, д.т.н., професор. 